\title{
Lake spray aerosol generation: a method for producing representative particles from freshwater wave breaking
}

\author{
Nathaniel W. May ${ }^{1}$, Jessica L. Axson ${ }^{2}$, Alexa Watson ${ }^{1}$, Kerri A. Pratt ${ }^{1,3}$, and Andrew P. Ault ${ }^{1,2}$ \\ ${ }^{1}$ Department of Chemistry, University of Michigan, Ann Arbor, Michigan 48109, USA \\ ${ }^{2}$ Department of Environmental Health Sciences, University of Michigan, Ann Arbor, \\ Michigan 48109, USA \\ ${ }^{3}$ Department of Earth and Environmental Sciences, University of Michigan, Ann Arbor, \\ Michigan 48109, USA
}

Correspondence to: Andrew P. Ault (aulta@umich.edu) and Kerri A. Pratt (prattka@umich.edu)

Received: 3 April 2016 - Published in Atmos. Meas. Tech. Discuss.: 17 May 2016

Revised: 11 August 2016 - Accepted: 16 August 2016 - Published: 6 September 2016

\begin{abstract}
Wave-breaking action in bodies of freshwater produces atmospheric aerosols via a similar mechanism to sea spray aerosol (SSA) from seawater. The term lake spray aerosol (LSA) is proposed to describe particles formed by this mechanism, which have been observed over the Laurentian Great Lakes. Though LSA has been identified from size distribution measurements during a single measurement campaign, no measurements of LSA composition or relationship to bubble-bursting dynamics have been conducted. An LSA generator utilizing a plunging jet, similar to many SSA generators, was constructed for the generation of aerosol from freshwater samples and model salt solutions. To evaluate this new generator, bubble and aerosol number size distributions were measured for salt solutions representative of freshwater $\left(\mathrm{CaCO}_{3}\right)$ and seawater $(\mathrm{NaCl})$ at concentrations ranging from that of freshwater to seawater $(0.05-$ $35 \mathrm{~g} \mathrm{~kg}^{-1}$ ), synthetic seawater (inorganic), synthetic freshwater (inorganic), and a freshwater sample from Lake Michigan. Following validation of the bubble and aerosol size distributions using synthetic seawater, a range of salt concentrations were investigated. The systematic studies of the model salts, synthetic freshwater, and Lake Michigan sample indicate that LSA is characterized by a larger number size distribution mode diameter of $300 \mathrm{~nm}$ (lognormal), compared to seawater at $110 \mathrm{~nm}$. Decreasing salt concentrations from seawater to freshwater led to greater bubble coalescence and formation of larger bubbles, which generated larger particles and lower aerosol number concentrations. This resulted in a bimodal number size distribution with a primary mode
\end{abstract}

$(180 \pm 20 \mathrm{~nm})$ larger than that of SSA, as well as a secondary mode $(46 \pm 6 \mathrm{~nm})$ smaller than that of SSA. This new method for studying LSA under isolated conditions is needed as models, at present, utilize SSA parameterizations for freshwater systems, which do not accurately predict the different size distributions observed for LSA or resulting climate properties. Given the abundance of freshwater globally, this potentially important source of aerosol needs to be thoroughly characterized, as the sizes produced are relevant to light scattering, cloud condensation nuclei (CCN), and ice nuclei (IN) concentrations over bodies of freshwater.

\section{Introduction}

Particles produced from wave breaking in marine environments, known as sea spray aerosol (SSA), are one of the largest sources of naturally generated aerosol to the atmosphere (Andreae and Rosenfeld, 2008; Lewis and Schwartz, 2004). SSA contributes to both direct and indirect radiative forcing on a global scale (Lohmann and Feichter, 2005; Murphy et al., 1998). Aerosol generation from freshwater sources, such as the Laurentian Great Lakes, has been far less studied, with only a single ambient measurement (Slade et al., 2010) and modeling study (Chung et al., 2011) having examined the process to our knowledge. Slade et al. (2010) observed the production of ultrafine $(<40 \mathrm{~nm})$ aerosol, which increased in concentration as a function of wind speed, during periods of white-capped waves over Lake Michigan. 
Through regional modeling, Chung et al. (2011) found that these particles could increase surface level aerosol number concentrations, by $\sim 20 \%$ over the remote northern Great Lakes and by $\sim 5 \%$ over other parts of the Great Lakes, potentially affecting cloud nuclei (CCN) and/or ice nuclei (IN) concentrations over the Great Lakes region. Recently, aerosols produced from freshwater (a river) were demonstrated to have enhanced ability to act as IN, in comparison with SSA (Moffett, 2016). Since even a small number of IN can have large impacts on clouds and precipitation (Ault et al., 2011; Creamean et al., 2013, 2015, 2016; DeMott et al., 2010), including SSA (DeMott et al., 2016), this shows the potential for LSA to impact climate.

It should be noted that the Chung et al. (2011) study was challenging because of the need to use SSA-based parameterizations derived from bubble bursting of higher-salinity seawater due to the lack of a bubble-bursting parameterization for lower-salinity freshwater. Due to their inherent differences from SSA, the term lake spray aerosol (LSA) is proposed to refer to aerosol formed from breaking waves in freshwater. Based on the intrinsic differences between SSA and LSA, and the heterogeneous water properties between and within the Great Lakes, methods are needed to understand aerosol production across a wide range of ionic and organic concentrations (Chapra et al., 2012; Shuchman et al., 2013).

Breaking waves, caused by winds that entrain air beneath the water's surface, form bubbles that rise to the surface and burst to eject droplets into the atmosphere (Lewis and Schwartz, 2004). Therefore, droplet production flux is generally modeled as a function of increasing wind speed (Lewis and Schwartz, 2004). Over freshwater higher wind speeds are necessary to generate whitecaps, the product of bubbles formed by breaking waves rising to the surface, in comparison to seawater (Monahan, 1969). The minimum wind speed necessary for freshwater whitecap production was observed by Monahan (1969) to be $7-8 \mathrm{~m} \mathrm{~s}^{-1}$ over the Laurentian Great Lakes, compared to a threshold wind velocity for seawater whitecap production at $3-4 \mathrm{~m} \mathrm{~s}^{-1}$ (Blanchard, 1963). However, wind speeds greater than this minimum wind speed necessary to produce breaking waves are still observed on large bodies of freshwater, such as the Laurentian Great Lakes (Monahan, 1969; Slade et al., 2010), which have a yearly mean wind speed $>6.6 \mathrm{~m} \mathrm{~s}^{-1}$ at a height of $10 \mathrm{~m}$ above the lake surface for the majority of the Laurentian Great Lakes (Doubrawa et al., 2015). In addition to differences in the wind speed necessary for whitecap formation, the lifetime of freshwater whitecaps is shorter than saltwater whitecaps (Monahan and Zietlow, 1969). Combined, the higher minimum wind speed necessary for whitecap formation and shorter whitecap lifetime in freshwater compared to seawater whitecap are anticipated to lead to less aerosol production from bubble bursting in freshwater than seawater.

To produce aerosols from freshwater using this mechanism, inorganic ions or other non-volatile material must

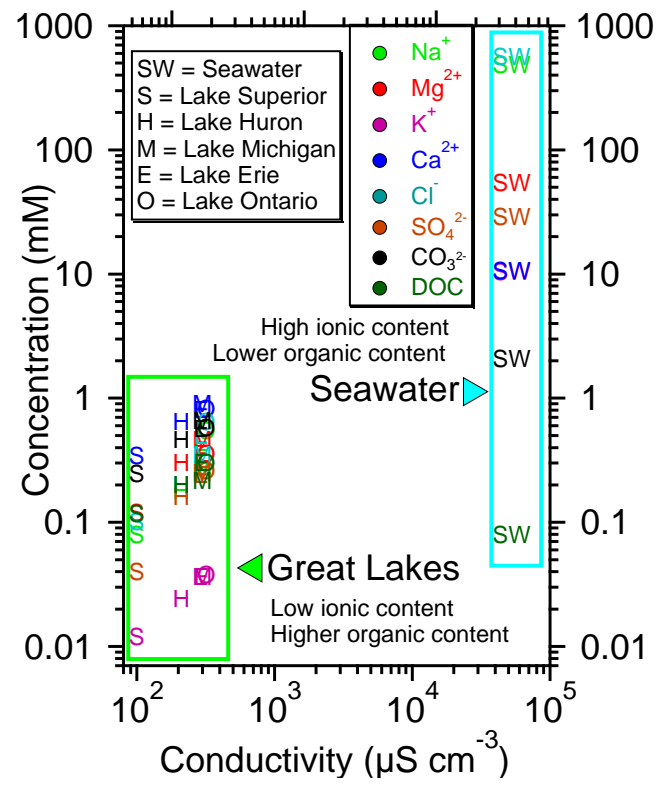

Figure 1. Concentration vs. conductivity vs. of important ions $\left(\mathrm{Na}^{+}, \mathrm{Mg}^{2+}, \mathrm{K}^{+}, \mathrm{Ca}^{2+}, \mathrm{Cl}^{-}, \mathrm{SO}_{4}^{2-}\right.$, and $\left.\mathrm{CO}_{3}^{2-}\right)$ for freshwater (Great Lakes) and mean seawater, as well as DOC. Great Lakes ion concentrations and conductivity are from Chapra et al. (2012), and seawater ion concentrations and conductivity are from Pilson (2013). TOC values for the Great Lakes are from Repeta et al. (2002), Shuchman et al. (2013), and Biddanda and Cotner (2002), while the TOC value for seawater is from Repeta et al. (2002). Note: $\mathrm{K}^{+}$is fully obscured for seawater by $\mathrm{Ca}^{2+}$.

be present in the droplets to form a dry particle after water evaporation. The Laurentian Great Lakes contain inorganic ions (Chapra et al., 2012) and dissolved organic carbon (DOC) (Shuchman et al., 2013), though differing in concentration and composition from that found in the ocean. Figure 1 shows the concentrations of a range of important ions and total organic carbon as a function of total water conductivity (Biddanda and Cotner, 2002; Chapra et al., 2012; Pilson, 2013; Repeta et al., 2002; Shuchman et al., 2013). Three key aspects of Great Lakes freshwater highlight the differences from seawater: (1) $2-5$ orders of magnitude lower inorganic ions concentrations, (2) different relative concentrations of key inorganic ions $\left(\mathrm{Ca}^{2+}>\mathrm{Mg}^{2+} \approx \mathrm{Na}^{+} \approx \mathrm{Cl}^{-}>\mathrm{SO}_{4}^{2-}>\mathrm{K}^{+}\right)$, and (3) total organic carbon (TOC) concentrations on the same order of magnitude as total inorganic ion concentrations. These differences in ion concentrations and ratios between seawater and freshwater will lead to important differences in the properties of bubbles from wave breaking formed in the Great Lakes and, thus, lead to different physical and chemical properties of the resulting aerosol, in comparison to SSA.

Previous work determined the bubble size distributions present in the water column for freshwater and seawater during laboratory simulations of wave breaking (Blenkinsopp and Chaplin, 2011; Carey et al., 1993; Monahan and Ziet- 
low, 1969; Slauenwhite and Johnson, 1999; Spiel, 1994a). An increase in the concentration of $<1 \mathrm{~mm}$ bubbles in seawater compared to freshwater primarily is thought to be due to differences in bubble coalescence (Blenkinsopp and Chaplin, 2011; Carey et al., 1993; Monahan and Zietlow, 1969). The higher ion concentrations in seawater inhibit bubble coalescence, leading to a higher proportion of small bubbles. In contrast, bubble coalescence occurs more freely in freshwater due to lower ion concentrations, which leads to a higher proportion of large bubbles (Lessard and Zieminski, 1971). Slauenwhite and Johnson (1999) suggest that, in addition to coalescence, an increase in the initial break-up of bubbles in seawater vs. freshwater causes a shift to larger diameters in the bubble size distributions for freshwater. As droplet, and subsequent dry particle, production is, in part, dependent on the bubble size distribution (Prather et al., 2013; Stokes et al., 2013), the increase in smaller bubbles in seawater compared to freshwater contributes to a different number size distribution of droplets, and therefore aerosol, produced by bubble bursting in freshwater compared to seawater. However, the bubble size distribution does not fully control the number size distribution of aerosols produced by bubble bursting. The concentration and composition of freshwater and seawater will further alter the dry particle formation by controlling the mass that remains, and thus the size, of a dry particle resulting from a droplet produced by bubble bursting. Droplets produced by bubble bursting in freshwater will have lower solute concentrations, and will form a smaller dry particle than those produced by bubble bursting in seawater, if the initial droplet is the same size (Slade et al., 2010).

To examine aerosol production from freshwater wave breaking, an LSA generator was constructed based on design elements from multiple validated laboratory SSA generators (Facchini et al., 2008; Fuentes et al., 2010; Hultin et al., 2010; King et al., 2012; Salter et al., 2014; Sellegri et al., 2006; Stokes et al., 2013; Zábori et al., 2012). The LSA generator can produce aerosols from a relatively small amount of freshwater, lowering the limitations surrounding the collection, transport, storage, and analysis of large surface lake water samples. This increases the possible number and variety of environmental samples that can be analyzed in a region with heterogeneous water properties. Systematic experiments were conducted in the LSA generator to determine the relationship between bubble size distributions and the resulting aerosol size, concentration, and composition. The bubble and aerosol properties were tested for simple salt solutions $\left(\mathrm{NaCl}\right.$ and $\left.\mathrm{CaCO}_{3}\right)$, simulated inorganic seawater and freshwater solutions, and a surface water sample from Lake Michigan. This study establishes a method to probe LSA with an interdisciplinary approach that draws from atmospheric science (production fluxes), physical oceanography (bubble measurements), atmospheric chemistry (aerosol physicochemical properties), and limnology (Great Lakes water properties). This work will broaden understanding of the effect of ion concentration and composition on aerosol production and properties, allowing for improved parameterization of LSA production from the Laurentian Great Lakes and other bodies of freshwater.

\section{Materials and methods}

\subsection{Materials}

Synthetic seawater was produced using Instant Ocean ${ }^{\mathrm{TM}}$ (Atkinson and Bingman, 1997) prepared with $18.2 \mathrm{M} \Omega$ ultrapure water. All remaining standard solutions were prepared using $18.2 \mathrm{M} \Omega$ ultrapure water and anhydrous analytical-grade inorganic salts $(\mathrm{NaCl} \geq 99 \%$ and $\mathrm{CaCO}_{3} \geq 99 \%$; Fisher Scientific). A solution of $1 \mathrm{mmol} \mathrm{Ca}^{2+}, 1 \mathrm{mmol} \mathrm{CO}_{3}^{2-}, \quad 0.4 \mathrm{mmol} \mathrm{Mg}^{2+}$, $0.4 \mathrm{mmol} \mathrm{SO}_{4}^{2-}, 0.3 \mathrm{mmol} \mathrm{Na}^{+}, 0.3 \mathrm{mmol} \mathrm{Cl}^{-}$, and $0.02 \mathrm{mmol} \mathrm{K}^{+}$was prepared as synthetic freshwater based on Lake Michigan ion concentrations reported by Chapra et al. (2012). Freshwater was collected from the surface of Lake Michigan near Muskegon, Michigan (43 $14^{\prime} 21.545 \mathrm{~N}$, $86^{\circ} 20^{\prime} 45.153 \mathrm{~W}$ ), on 26 July 2015 in an 8 L LDPE carboy. During freshwater sampling, a multi-parameter water quality sensor (Professional Plus, YSI, Inc.) was used to measure freshwater properties, including temperature, $\mathrm{pH}$, salinity, and dissolved oxygen, and a handheld spectrophotometer (AquaFluor 8000) was used to measure blue-green algae content. The freshwater was frozen after sampling for storage and thawed prior to analysis. Frozen freshwater samples that have been thawed were analyzed by nanoparticle tracking analysis, which measures the size distribution and number concentration of insoluble residues (Axson et al., 2014). The frozen samples did not show changes in size or number concentration of insoluble components compared to unfrozen samples, indicating the sample was likely not significantly modified by freezing (Axson et al., 2016b).

\subsection{Aerosol generation}

An LSA generator (Fig. 2) was constructed based on a design incorporating elements from previously published laboratory SSA generators (Fuentes et al., 2010; Hultin et al., 2010; Salter et al., 2014; Sellegri et al., 2006; Stokes et al., 2013). The LSA generator consists of an acrylic box with a total volume of $18 \mathrm{~L}(30 \times 20 \times 30 \mathrm{~cm})$ and a water circulating system controlled using a diaphragm pump (ShurFlo 2088). Water was circulated from the tank and cycled back into the tank at a rate of $2 \mathrm{~L} \mathrm{~min}^{-1}$ as plunging jets from four tubes ( $1 / 8 \mathrm{in}$. inner diameter) arranged in a square pattern $5 \mathrm{~cm}$ apart at the top of the tank, approximately $20 \mathrm{~cm}$ above the water surface (depending on fill level). Air was entrained by the plunging jets, creating a bubble plume of approximately $5 \mathrm{~cm}$ in depth with $5 \mathrm{~cm}$ between the plume and the base of the chamber, analogous to the wave-breaking mechanism observed in nature (Fuentes et al., 2010). The four tubes 

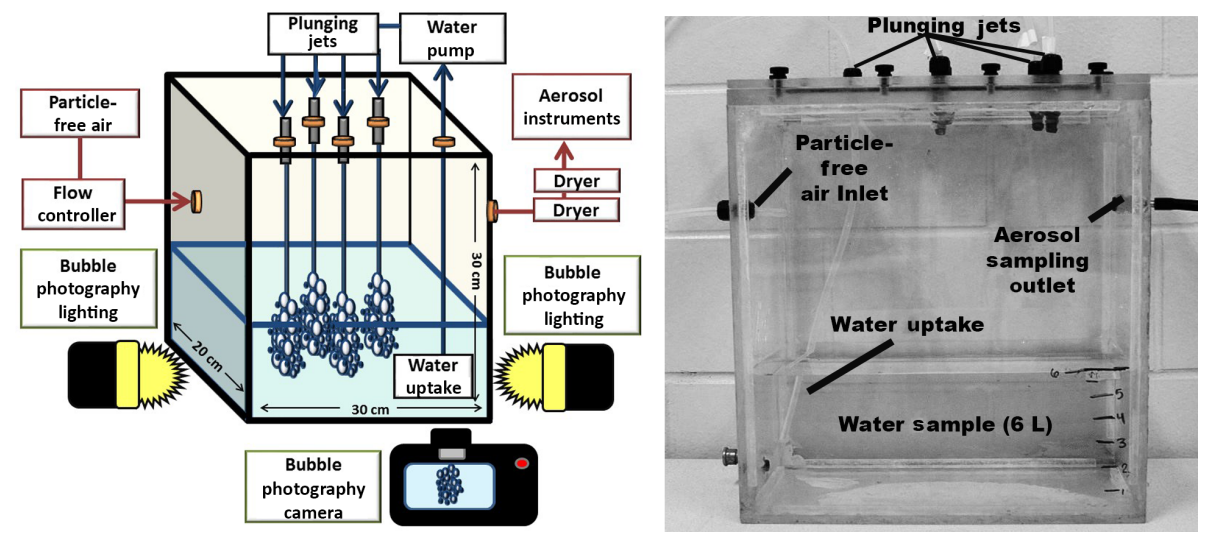

Figure 2. The constructed lake spray aerosol generator shown as a (a) schematic and (b) photograph with functional components labeled. Not all components of the LSA generator shown in the schematic are visible in the photograph.

were capped with mesh to break up the flow and increase the surface roughness of the plunging jet before it hit the water surface in order to obtain an accurate bubble size distribution (Stokes et al., 2013; Zhu et al., 2000). Prior to each experiment, the LSA generator was rinsed with $18.2 \mathrm{M} \Omega$ ultrapure water. Prior to and during operation, HEPA-filtered particle-free air was pulled through the LSA generator to prevent ambient particle contamination as flow was pulled to the instruments. The LSA generator was maintained at positive pressure with a constant overflow of $0.2 \mathrm{~L} \mathrm{~min}^{-1}$. All experiments were performed at room temperature, approximately $22.0^{\circ} \mathrm{C}$, and the relative humidity $(\mathrm{RH})$ within the tank was maintained at $\sim 85 \%$, the standard RH for ambient and laboratory SSA generation (Lewis and Schwartz, 2004).

A major advantage of the LSA generator system is that it needs a relatively small volume of water (4-6L) compared to other SSA generation systems (100 L) (Salter et al., 2014; Stokes et al., 2013). However, the shallow bubble plume generated in plunging water jet systems of reduced dimensions such as the one discussed in this study $(5 \mathrm{~cm})$, and others (Fuentes et al., 2010; Hultin et al., 2010; Sellegri et al., 2006), limits bubble plume lifetime, as discussed in detail by Fuentes et al. (2010). Large-volume plunging jets with plume depths $>0.5 \mathrm{~m}$ are expected to be representative of the lifetime of oceanic plumes (Collins et al., 2014; Stokes et al., 2013), but those are only suitable when large amounts of sample are available. Due to difficulties in obtaining and storing large volume freshwater samples from multiple collection sites, these types of large-scale aerosol generation methods are not suitable for our research. In addition, work by Fuentes et al. (2010) demonstrated that the shortened bubble plume lifetime does not affect the adsorption of marine surfactant to rising bubbles in small-volume SSA generation methods and that these systems are appropriate for studying the effects of marine organics on SSA. Therefore, the LSA generator presented in this work, despite its reduced dimen- sions, should be suitable for the study of the effect freshwater composition on LSA production.

\subsection{Bubble size distribution measurements}

Digital high-speed photographs of the LSA generator plunging jet bubble plume were collected to examine the bubble size distributions. The bubbles were photographed using a Nikon D100 camera fitted with an AF Nikkor 24-50 mm lens and placed approximately $45 \mathrm{~cm}$ from the front of the tank to capture side profiles of the bubble plume. An aperture of 4.5 was used to achieve the narrowest depth of field possible in the resulting images. To increase bubble clarity, two light sources (Ring 48, Neewer) were placed to the right and left of the tank, illuminating the bubbles (Fig. 2). Photographs were obtained at intervals $>60 \mathrm{~s}$ to ensure each bubble was counted only once (Salter et al., 2014).

ImageJ was used to determine the bubble plume size distribution in each photograph. Individual bubbles were manually identified and a circle was fit to each bubble (Schneider et al., 2012). The bubble dimensions obtained in pixels were converted to millimeters by a scaling factor calculated for individual photographs in the ImageJ software from measurements of a portion of the tank with known length visible in the photograph. The area was then converted to diameter, reported here in millimeters, assuming the bubbles to be circular (Lewis and Schwartz, 2004). In determining the bubble volume density, the volume of the bubble plume was calculated from measurements of plume photographs in ImageJ. Due to interferences of light diffraction in the LSA generator and limitations in the camera, such as pixel size and resolution, bubbles $<100 \mu \mathrm{m}$ in diameter could not be distinguished accurately from the background of the photograph and are not included in the analysis. Another limitation inherent in this method is that it is possible that a smaller fraction of bubbles in the focal volume were obscured by other bubbles and not counted. 


\subsection{Aerosol size distribution measurements}

Aerosols generated by bubble bursting exited the LSA generator and passed through two silica gel diffusion dryers to achieve a RH of $\sim 15 \%$, similar to the $\mathrm{RH}$ of previous measurements of aerosol size distributions of laboratory SSA (Fuentes et al., 2010; Salter et al., 2014; Stokes et al., 2013). After exiting the diffusion driers, the aerosol number size distributions and total aerosol concentrations produced for each solution in the LSA generator were measured using a scanning mobility particle sizer (SMPS), consisting of a differential mobility analyzer (DMA; model 3082, TSI Inc.) and condensation particle counter (CPC; model 3775, TSI Inc.), as well as an aerodynamic particle sizer (APS; model 3321, TSI Inc.). The SMPS operated at a sample flow rate of $0.3 \mathrm{~L} \mathrm{~min}^{-1}$ and sheath flow of $3 \mathrm{~L} \mathrm{~min}^{-1}$ and a scan rate of 5 min to obtain a size distribution for particles with an electrical mobility diameter $\left(d_{\mathrm{m}}\right)$ between 14.1 and $736.5 \mathrm{~nm}$. The APS was operated at a flow rate of $5.0 \mathrm{~L} \mathrm{~min}^{-1}$, with an aerosol and sheath flow of 1.0 and $4.0 \mathrm{~L} \mathrm{~min}^{-1}$, respectively, and a scan rate of $30 \mathrm{~s}$ to obtain a size distribution for particles with an aerodynamic diameter $\left(d_{\mathrm{a}}\right)$ between $<0.52$ and $19.8 \mu \mathrm{m}$. For each sample solution, SMPS and APS particle size distributions were collected over a $3 \mathrm{~h}$ period and averaged. In order to merge the SMPS and APS size distribution, measurements recorded in $d_{\mathrm{m}}$ and $d_{\mathrm{a}}$, respectively, were converted to physical (geometric) diameters $\left(d_{\mathrm{p}}\right)$ (Khlystov et al., 2004). The relation

$d_{\mathrm{m}}=d_{\mathrm{p}}$

was used to convert particles sized by the SMPS, under the assumption that the particles were spherical. Particles sized by the APS were assigned an effective density $\left(\rho_{\text {eff }}\right)$ of $1.2-$ $1.6 \mathrm{~g} \mathrm{~cm}^{-3}$, a value determined experimentally for particles produced from each individual solution, allowing for conversion based on the following relation:

$d_{\mathrm{p}}=\frac{d_{\mathrm{a}}}{\sqrt{\frac{\rho_{\mathrm{eff}}}{\rho_{0}}}}$,

where $\rho_{0}$ is equal to unit density $\left(1 \mathrm{~g} \mathrm{~cm}^{-3}\right)$. The SMPS has a tendency to undercount particle concentrations at the highest particle diameter bins, due to the cut-off from the particle impactor, and the APS has a tendency to undercount particle concentrations at the lower diameter bins, due to the poor scattering efficiency of the lowest particle diameter bins (Ault et al., 2009; Khlystov et al., 2004; Qin et al., 2006). To compensate for these limitations, the highest and lowest particle diameter bins of the SMPS and APS, respectively, comprising the overlapping diameters of the two methods, were removed when stitching (Stokes et al., 2013). All reported aerosol size distribution modes are from fits of lognormal distributions. Aerosol blank measurements conducted before experiments by circulating $18.2 \mathrm{M} \Omega$ ultrapure water through the LSA generator showed that the background aerosol number concentrations were $<20 \mathrm{~cm}^{-3}$, compared to an average of $350 \mathrm{~cm}^{-3}$ during freshwater samples.

\subsection{Scanning electron microscopy}

Particles generated from the different solutions run in the LSA generator were impacted onto carbon type-B (Formvar film coated with carbon on copper grid) transmission electron microscopy (TEM) grids (01910-F, Ted Pella, Inc.) using a three-stage microanalysis particle sampler (MPS; model MPS-3, California Measurements, Inc.). Particles were examined from the third (smallest) stage, with a size cut of $<700 \mathrm{~nm}$. Scanning electron microscopy with energy dispersive X-ray (SEM-EDX) measurements were made at the Michigan Center for Materials Characterization (MC) ${ }^{2}$ located at the University of Michigan in Ann Arbor. An FEI Helios with environmental dual focused ion beam-scanning electron microscope (FIB-SEM) was used to obtain images of the particles. The FEI Helios was equipped with a Schottky field emitting source operating at an accelerating voltage of $15 \mathrm{kV}$ and current of $0.58 \mathrm{nA}$. Scanning transmission electron microscopy (STEM) was conducted and a high-angle annular dark-field (HAADF) electron detector was used to collect Z-dependent dark-field images of individual particles.

\section{Results and discussion}

\subsection{Comparison of seawater and freshwater bubble plume size distributions}

Photographs of bubble plumes generated from synthetic seawater, synthetic freshwater, and Lake Michigan freshwater were collected to observe visual changes in bubble plumes and to determine their respective bubble size distributions (Fig. 3). There was an observed decrease in the concentration of smaller bubbles in freshwater when compared to synthetic seawater, which has been observed in previous studies (Blenkinsopp and Chaplin, 2011; Carey et al., 1993; Monahan and Zietlow, 1969; Slauenwhite and Johnson, 1999; Spiel, 1994b). The visual differences in the images were reflected in the measured bubble size distributions (Fig. 3d), with the synthetic freshwater and Lake Michigan freshwater samples producing a similar total bubble concentration that was only 12 and $8 \%$ (Fig. 3e), respectively, of the total bubble concentration produced from the synthetic seawater solution. Bubble size distributions generated from synthetic seawater showed that bubbles were produced up to $4 \mathrm{~mm}$ in radius in the LSA generator (Fig. 3d), similar to measurements of bubble size distributions for ocean waves (Bowyer, 2001; Deane, 1997; Deane and Stokes, 1999, 2002).

The production of bubbles with radii $>1 \mathrm{~mm}$ is important because droplet production from bubble bursting, and the resulting dry particle size distribution, is dependent on 

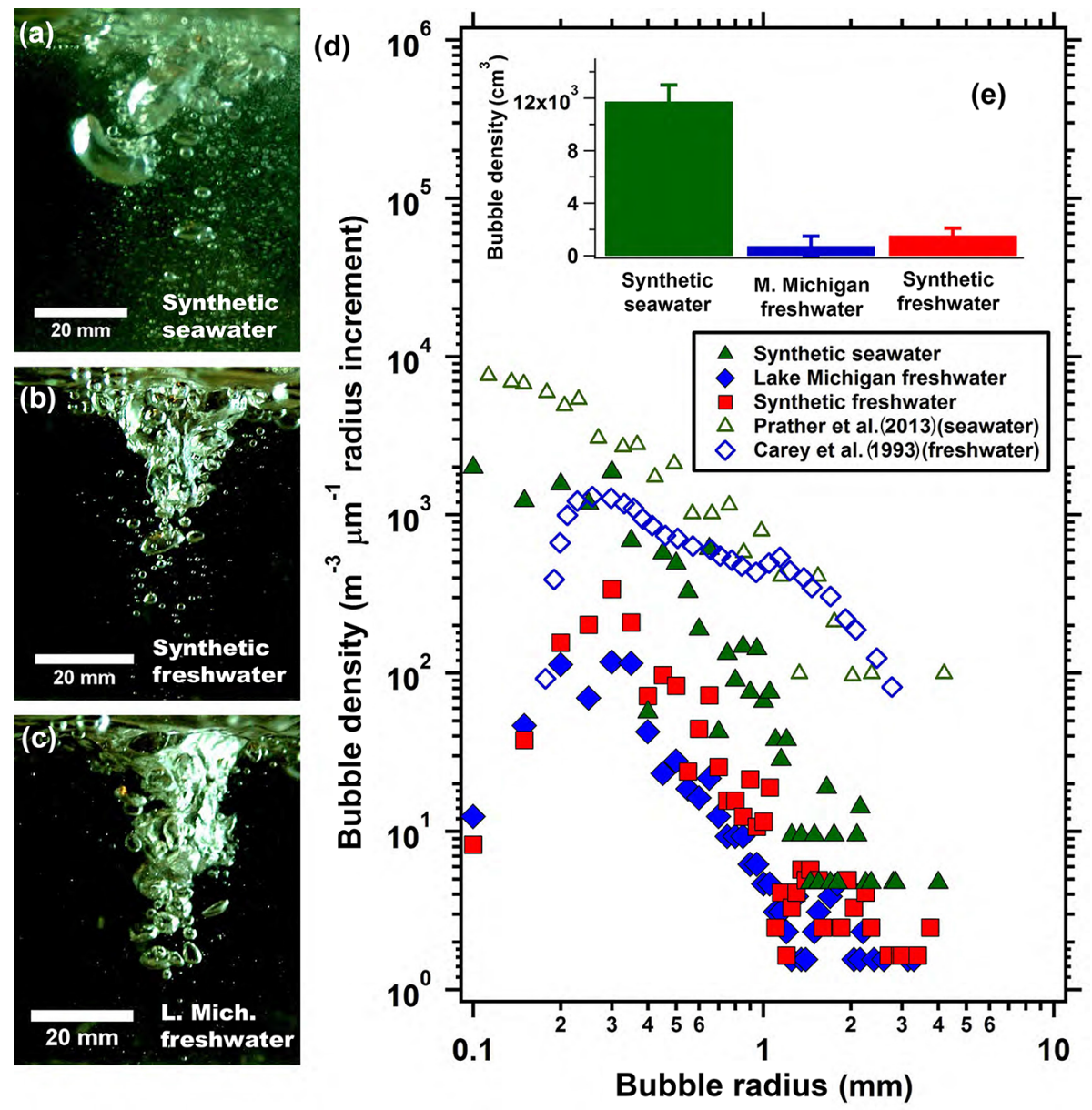

Figure 3. Digital images of a bubble plume generated by one plunging jet in the LSA generator with (a) synthetic seawater, (b) synthetic freshwater, and (c) Lake Michigan freshwater, with brightness/contrast adjusted to increase bubble clarity. (d) Bubble number size distributions and (e) bubble concentrations generated by the LSA generator using synthetic seawater, synthetic freshwater, and Lake Michigan freshwater measured by the bubble photography method, as well as previously measured bubble size distributions generated from synthetic seawater with a plunging waterfall (Prather et al., 2013) and freshwater with a tipping trough (Carey et al., 1993).

bubble size (Collins et al., 2014). The bubble-bursting process in seawater ejects two types of droplets into the atmosphere: film and jet droplets (Blanchard and Syzdek, 1975; Blanchard and Woodcock, 1957). Film and jet droplets typically range in size from 0.2 to 10 and 1 to $200 \mu \mathrm{m}$, respectively (Lewis and Schwartz, 2004). The number of film and jet droplets produced from a single bubble in seawater is dependent on the size of the bubble, and bubbles with radii $>1 \mathrm{~mm}$ produce more film drops and bubbles $<1 \mathrm{~mm}$ produce jet drops in quantities greater than 1 per bubble (Lewis and Schwartz, 2004). In addition, jet drop size is directly correlated to bubble size (Lewis and Schwartz, 2004). If bubbles $>1 \mathrm{~mm}$ are not produced by a generation method, then a higher proportion of jet droplets will be formed, shifting the aerosol size distribution mode and modifying the aerosol chemical composition (Collins et al., 2014; Stokes et al., 2013). The replication of this power law decrease in bubble concentrations at larger radii using the LSA genera- tor is therefore critical for the accurate reproduction of SSA (Prather et al., 2013; Stokes et al., 2013) and LSA.

The bubble radius mode for the synthetic freshwater and Lake Michigan freshwater bubble size distributions were observed at $280 \pm 70$ and $250 \pm 60 \mu \mathrm{m}$, respectively (Fig. 3d). This is consistent with freshwater laboratory measurements by Carey et al. (1993), which show a mode of $300 \mu \mathrm{m}$ and a steep drop in bubble concentration for radii below $300 \mu \mathrm{m}$ (Fig. 3d). This bubble size mode is much larger than that observed for seawater, for which bubble size distributions typically peak at a radius between 40 and $80 \mu \mathrm{m}$ (Fuentes et al., 2010; Hultin et al., 2010; Prather et al., 2013; Sellegri et al., 2006; Stokes et al., 2013). This means the peak mode for the synthetic seawater bubble size distribution produced in the LSA generator was below the detectable bubble size limit of the photographic technique used in this study. Indeed, the LSA generator bubble size distribution for seawater in Fig. 3d has a peak mode lower than that for fresh- 
water and is $<100 \mu \mathrm{m}$. Previous work examining seawater bubble size distributions have encountered this same measurement limitation (Carey et al., 1993; Deane and Stokes, 2002; Hultin et al., 2010), which was resolved by comparing the power-law-dependent decrease in bubble concentrations at higher radii to confirm the accuracy of bubble size distribution. Results from this comparison, presented in the Supplement, are consistent with previous observations and confirm that the LSA generator produces bubble plumes representative of both oceanic and freshwater wave breaking.

However, the concentrations of bubbles produced from both freshwater and seawater samples in the LSA generator were lower than the concentrations representative of freshwater (Carey et al., 1993) and seawater (Stokes et al., 2013) wave breaking previously reported (Fig. 3d). Further, the lower concentration of bubbles compared to previous measurements is more pronounced at larger radius $(>1 \mathrm{~mm})$ bubbles. This limitation of the LSA generator is likely due to its reduced dimensions compared to the bubble generation methods used for comparison (Carey et al., 1993; Stokes et al., 2013). The smaller dimensions allow for small sample volumes, but likely limit the lifetime of the bubble plumes (Fuentes et al., 2010), as discussed in Sect. 2.2.

\subsection{Aerosol generation from seawater and freshwater}

\subsubsection{Validation of aerosol generated with synthetic seawater}

To both characterize the LSA generator and compare freshwater aerosols to those generated from seawater, aerosol size distributions generated from synthetic seawater, synthetic freshwater, and Lake Michigan freshwater were measured (Fig. 4). The aerosol size distribution generated for synthetic seawater produced a total number concentration of $1195 \mathrm{~cm}^{-3}$ and exhibited a single mode at a diameter of $110 \pm 4 \mathrm{~nm}$, with a geometric standard deviation $(\sigma)$ of 1.52 , and an amplitude of $1620 \mathrm{~cm}^{-3}$ (Table 1). This SSA mode is in agreement with the primary diameters of SSA modes, which ranged from 60 to $200 \mathrm{~nm}$, determined using various laboratory generation techniques (Collins et al., 2014; Fuentes et al., 2010; Hultin et al., 2010; Prather et al., 2013; Salter et al., 2014; Sellegri et al., 2006; Stokes et al., 2013). It was determined that the LSA generator successfully reproduced seawater bubble and aerosol size distributions such that the system can be used to test other applications.

\subsubsection{Characteristics of aerosol generation from freshwater}

The synthetic freshwater and Lake Michigan freshwater produced 67 and $33 \%$ lower total aerosol number concentrations $\left(d_{\mathrm{p}}=0.018-18 \mu \mathrm{m}\right)$, compared to the synthetic seawater, respectively (Fig. 4b). The lower total aerosol number concentration produced from the freshwater solutions, in compar-

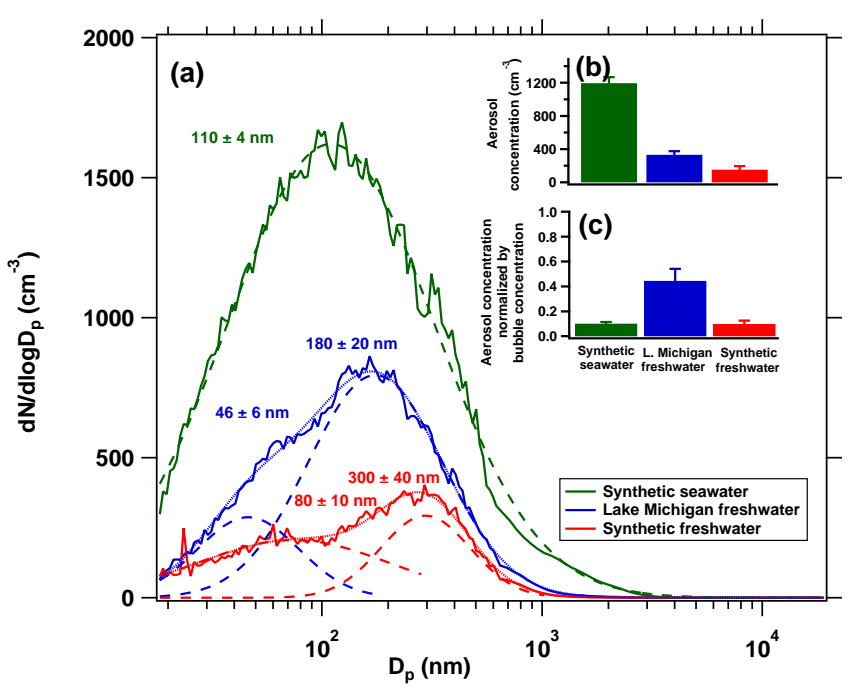

Figure 4. (a) Average aerosol number size distributions fitted with lognormal distributions (long dashes indicate each peak, while short dashes represent the sum of the peaks) (b) average total aerosol number concentration, and (c) average total aerosol number concentration normalized by average total bubble concentration produced by the LSA generator (particles per bubble) from synthetic seawater, synthetic freshwater, and Lake Michigan freshwater.

ison to the synthetic seawater, is a reflection of the lower bubble concentrations produced from the freshwater solutions in comparison to synthetic seawater (Figs. 4b, 5). However, it is important to note that the Lake Michigan freshwater produced a larger total aerosol concentration normalized by the total bubble concentration generated than both the synthetic freshwater and the synthetic seawater solution, which were both similar (Fig. 4c). In contrast to the unimodal synthetic seawater aerosol size distribution, both the synthetic freshwater and Lake Michigan freshwater aerosol size distributions were bimodal (Fig. 4a and Table 1). The primary mode observed for the synthetic freshwater and Lake Michigan freshwater occurred at a diameter of $300 \pm 40$ and $180 \pm 20 \mathrm{~nm}$, respectively, which are larger than the dominant mode observed for synthetic seawater $(110 \pm 4 \mathrm{~nm})$. The secondary mode was observed at a diameter of $80 \pm 10 \mathrm{~nm}$ for the synthetic freshwater and $46 \pm 6 \mathrm{~nm}$ for the Lake Michigan freshwater sample. The LSA secondary mode for the Lake Michigan freshwater is similar to previous aircraft measurements by Slade et al. (2010), who observed a $15-40 \mathrm{~nm}$ particle lognormal diameter mode over Lake Michigan. Slade et al. (2010) performed calculations of expected dry particle diameter based on typical droplet size produced from oceanic wave breaking and total dissolved ion content of freshwater. These calculations indicated that the aerosol size distribution of LSA would peak at a diameter smaller than SSA, and this would explain the measured secondary mode generated from freshwater solutions in this study that was lower in diameter than the primary mode 
Table 1. Aerosol size distribution characteristics obtained from lognormal fitting for LSA generated from synthetic seawater, synthetic freshwater, and Lake Michigan freshwater.

\begin{tabular}{llrrr}
\hline Solution & Mode & $\begin{array}{r}\text { Diameter } \\
(\mathrm{nm})\end{array}$ & $\begin{array}{r}\text { Standard } \\
\text { deviation }(\sigma)\end{array}$ & $\begin{array}{r}\text { Amplitude } \\
\left(\mathrm{cm}^{-3}\right)\end{array}$ \\
\hline Synthetic seawater & Primary & $110 \pm 4$ & 1.52 & 1620 \\
Synthetic freshwater & Primary & $300 \pm 40$ & 1.00 & 292 \\
& Secondary & $80 \pm 10$ & 0.75 & 206 \\
L. Michigan freshwater & Primary & $180 \pm 20$ & 0.66 & 794 \\
& Secondary & $46 \pm 6$ & 1.42 & 286 \\
\hline
\end{tabular}

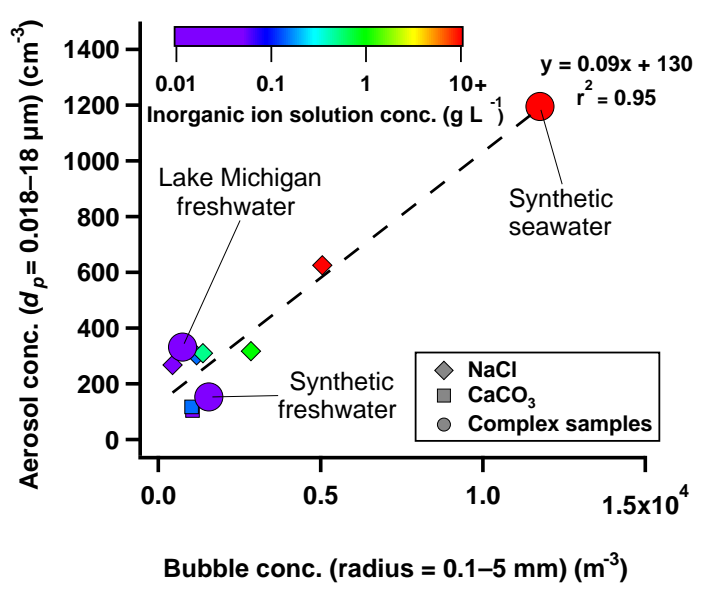

Figure 5. Aerosol vs. bubble concentrations produced by the LSA generator from solutions of $\mathrm{NaCl}$ and $\mathrm{CaCO}_{3}$ of varying concentrations, Lake Michigan freshwater, synthetic freshwater, and synthetic seawater. A best-fit line is shown for the empirical relationship between aerosol and bubble concentrations.

of SSA (see Sect. 3.2.3). These results indicate that wavebreaking-induced bubble bursting of freshwater in the Great Lakes can produce aerosols through mechanisms analogous to wave breaking on open oceans, but the size distribution of LSA has different characteristics than that of SSA.

The increased total particle concentration as well as the shift in diameter mode to smaller sizes, for the Lake Michigan freshwater sample compared to the synthetic freshwater, points to the possible additional influence of organic carbon present in the Lake Michigan freshwater sample. While the synthetic freshwater was a simplified mixture of inorganic ions representing freshwater, the Lake Michigan freshwater contained a more complex mixture of inorganic ions, as well as organic and biological material present in the surface water during collection. Like the synthetic freshwater, the synthetic seawater is a simplified mixture of inorganic ions representing seawater. The higher total particle concentration normalized by total bubble concentration observed for the Lake Michigan freshwater sample, compared to the total particle concentration normalized by total bubble concentration for the synthetic freshwater and synthetic seawater, fur- ther demonstrates the possible influence of organic carbon present in the Lake Michigan freshwater sample. The presence of biological material in the freshwater sample was confirmed by spectrophotometric measurements of bulk water at the site during sample collection, which indicated $57.2 \mathrm{ppb}$ of blue-green algae present. Given that the Lake Michigan freshwater sample was frozen prior to analysis, it is likely that the sample did not contain substantial living biological material when run in the LSA generator.

To further determine the influence of organic carbon between the Lake Michigan freshwater sample aerosol populations, impacted particles were analyzed by SEM to determine circularity (Fig. 6), which in seawater has been shown to increase with greater total organic carbon concentrations due to the interference of organic carbon with the crystallization process during drying on the substrate (Ault et al., 2013b). Particles generated from the Lake Michigan freshwater sample showed median circularity values approaching unity, indicative of a perfect circle (and thus a spherical particle in the atmosphere, as shown in Ault et al., 2012). In comparison, particles generated from the synthetic freshwater sample have circularity distributions peaking below 0.9 for all size ranges measured $(<0.5 \mu \mathrm{m}, 0.5-1.0$ and $>1 \mu \mathrm{m})$. This higher circularity is likely due to greater organic content in the authentic Lake Michigan sample vs. the inorganic-only synthetic freshwater sample. In addition, the complex salt mixture in the Great Lakes, where most ion concentrations are within an order of magnitude of each other $\left(\mathrm{Ca}^{2+}\right.$ and $\mathrm{CO}_{3}^{2-}$ being the largest), is more likely to affect crystallization than for seawater, where $\mathrm{Na}^{+}$and $\mathrm{Cl}^{-}$are present in concentrations that are an order of magnitude higher than any other inorganic ion (Fig. 1). Future efforts will involve systematic studies of aerosols generated from freshwater samples with a range of inorganic, organic, and biological components.

\subsubsection{Freshwater droplet size distribution to freshwater aerosol size distributions}

Calculations of the relationship between dry particle diameter and initial drop diameter were explored for seawater and freshwater to determine the effect of the initial droplet size distribution on aerosol formation. The physical diameter of a dry $(\mathrm{RH}=0 \%)$ SSA particle $\left(d_{\mathrm{p}}\right)$ will typically be $\sim 4 \times$ 


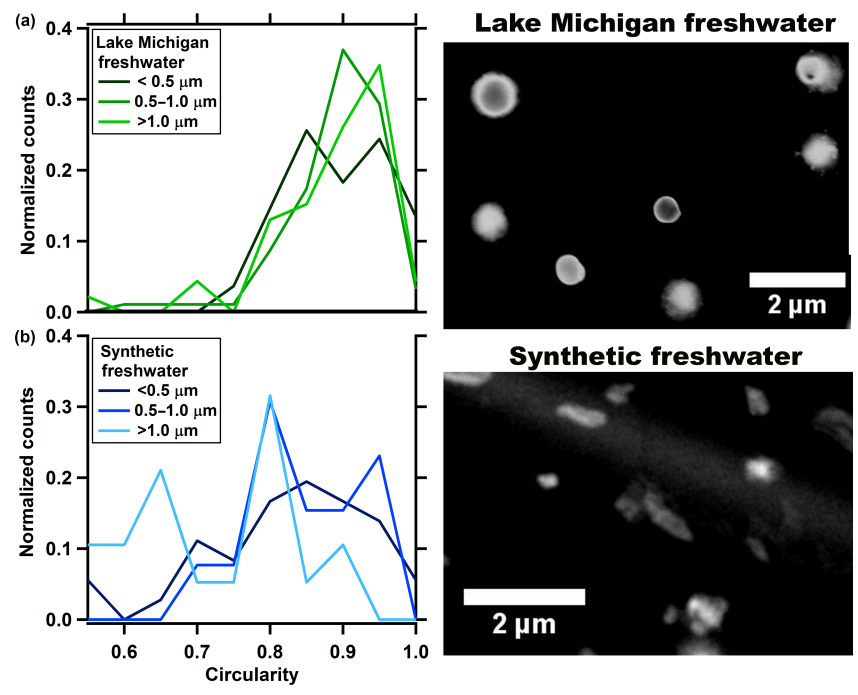

Figure 6. Circularity of (a) Lake Michigan freshwater particle sample and (b) synthetic freshwater particles as a function of diameter from the LSA generator, as well as example SEM images of the impacted particles used in the analysis.

Table 2. Fresh- and seawater droplet diameters $\left(d_{\mathrm{d}}\right)$ calculated from the mass (assuming particle density is $1.2 \mathrm{~g} \mathrm{~mL}^{-1}$ ) of the dominant dry particle diameter $\left(d_{0}\right)$ modes produced from synthetic seawater (SSA) and the Lake Michigan freshwater sample (LSA).

\begin{tabular}{ll}
\hline Observed dry diameter $\left(d_{0}\right)$ & Droplet diameter $\left(d_{\mathrm{d}}\right)$ \\
\hline $0.110 \mu \mathrm{m}$ SSA & $0.440 \mu \mathrm{m}$ seawater \\
$0.046 \mu \mathrm{m}$ LSA & $0.92 \mu \mathrm{m}$ freshwater \\
$0.180 \mu \mathrm{m}$ LSA & $3.5 \mu \mathrm{m}$ freshwater \\
\hline
\end{tabular}

smaller than the diameter of the seawater droplet $\left(d_{\mathrm{d}}\right)$ it originated from (Veron, 2015). Therefore, the $d_{\mathrm{p}}=110 \pm 4 \mathrm{~nm}$ aerosol mode generated from the synthetic seawater in the LSA generator would have resulted from a roughly $d_{\mathrm{d}}=$ $440 \mathrm{~nm}$ initial synthetic seawater droplet mode (Table 2). In contrast, due to the lower concentration of dissolved components in freshwater, the $d_{\mathrm{p}}$ of an LSA particle is predicted to be $\sim 20 \times$ smaller than the $d_{\mathrm{d}}$ of the freshwater droplet it originated from (Slade et al., 2010) (Table 2). Using this relationship Slade et al. (2010) predicted that the size distribution of LSA shifts towards smaller, ultrafine diameters in comparison to the size distribution of SSA. However, these calculations were made under the assumption freshwater and seawater bubble bursting produce the same $d_{\mathrm{d}}$ size distributions, which may not be accurate as there are differences in bubble size distributions generated in freshwater and seawater solutions (Fig. 3d).

Previous work, while limited, has shown differences in the size distribution of droplets produced from freshwater bubble bursting in comparison to droplet production from seawater bubble bursting (Resch, 1986). Resch (1986) observed that film drops produced from freshwater are larger than those usually reported for seawater, which for SSA can range in $d_{80}$ from 0.02 to $200 \mu \mathrm{m}$ (Lewis and Schwartz, 2004). Therefore, the smaller mode of the Lake Michigan freshwater aerosol size distribution $(46 \pm 6 \mathrm{~nm})$ observed in this study could be the result of a freshwater film droplet mode of $d_{\mathrm{d}}=920 \mathrm{~nm}$, which is larger than the $d_{\mathrm{d}} \approx 400 \mathrm{~nm}$ synthetic seawater film droplet mode (Table 2). The second mode $(180 \pm 20 \mathrm{~nm})$ of the observed Lake Michigan freshwater sample aerosol size distribution is likely the result of an even larger film droplet mode at $d_{\mathrm{d}}=3.5 \mu \mathrm{m}$. This second mode is unlikely to be the result of jet drop production as bubble bursting, in seawater, typically produces jet drops with a $d_{\mathrm{d}}$ that are $10 \%$ of the bubble diameter $\left(d_{\text {bub }}\right)$ (Lewis and Schwartz, 2004), and individual bubbles in freshwater and seawater produce jet drops at similar numbers and sizes from bubbles with radii of 300 $1500 \mu \mathrm{m}$ (Spiel, 1994b). Therefore, even the smallest freshwater bubble measured in this study $\left(d_{\text {bub }}=0.2 \mathrm{~mm}\right)$ would likely only produce jet drops of $d_{\mathrm{d}}=20 \mu \mathrm{m}$ and $d_{\mathrm{p}}=1 \mu \mathrm{m}$, a far higher diameter than the larger mode observed for the Lake Michigan sample (300 nm) (Fig. 4). Further work is needed to determine the differences in film droplet production between fresh and seawater bubble bursting to fully connect bubble and aerosol size distributions observed in this study.

\subsection{Aerosol and bubble generation from standard salt solutions}

\subsubsection{Bubble size and concentration from standard salts}

To determine the influence of the dominant inorganic ions, and their concentrations, in freshwater and seawater (Fig. 1) on bubble production, bubble size distributions for $\mathrm{NaCl}$ (seawater proxy) and $\mathrm{CaCO}_{3}$ (freshwater proxy) solutions were determined as a function of solution concentration (Fig. 7a, b). The radii modes of the bubble size distributions produced from $\mathrm{CaCO}_{3}$ solutions of 0.05 and $0.15 \mathrm{~g} \mathrm{~kg}^{-1}$ $(230 \pm 90 \mu \mathrm{m})($ Fig. $7 \mathrm{a})$ were similar to the synthetic freshwater $(280 \pm 70 \mu \mathrm{m})$ and Lake Michigan freshwater sample $(250 \pm 60 \mu \mathrm{m})$ bubble size distributions (Fig. 3d). This similarity in bubble size distribution radii modes is consistent with $\mathrm{Ca}^{2+}$ and $\mathrm{CO}_{3}^{2-}$ being the dominant cation and anion, respectively, in the calcareous Great Lakes (Chapra et al., 2012). No solutions of $\mathrm{CaCO}_{3}$ of concentration greater than $0.15 \mathrm{~g} \mathrm{~kg}^{-1}$ could be analyzed for bubble size distributions due to the solubility limit.

For $\mathrm{NaCl}$ solution concentrations 0.05 to $35 \mathrm{~g} \mathrm{~kg}^{-1}$, total bubble density increased with solution concentrations. The largest increase in bubble density ( $2-3$ orders of magnitude) primarily occurred for the smallest bubbles (radii $<0.3 \mathrm{~mm}$ ) (Fig. 7b), which is the same bubble size range as the largest increase (2-3 orders of magnitude) in bubble density between freshwater and seawater solutions that was observed 


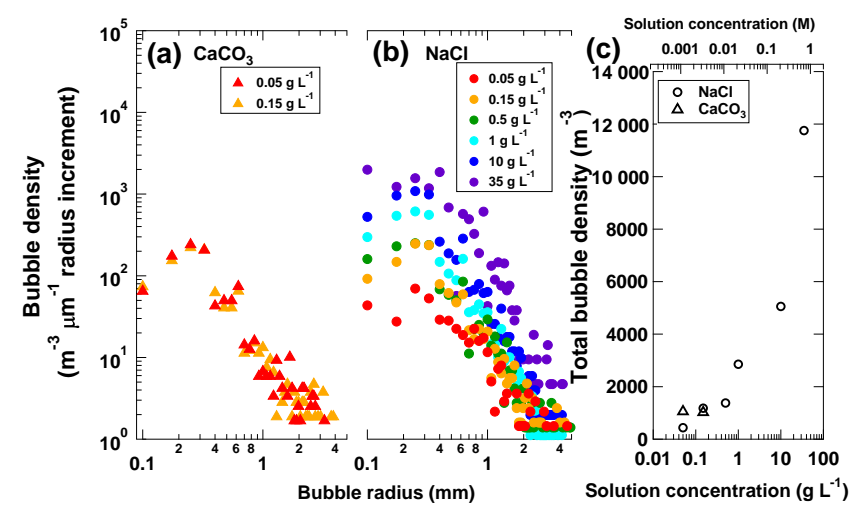

Figure 7. Bubble size distributions (density vs. bubble radius) generated by the LSA generator as a function of solution concentration for (a) $\mathrm{CaCO}_{3}$ and (b) $\mathrm{NaCl}$, as well as (c) total bubble density as a function of ion composition for $\mathrm{CaCO}_{3}$ and $\mathrm{NaCl}$.

(Fig. 3d). This observed increase in bubble density from freshwater to seawater concentration solutions is likely the result of bubble coalescence inhibition at higher ionic concentration (Slauenwhite and Johnson, 1999), as the two electrolyte combinations tested in this study $\left(\mathrm{CaCO}_{3}\right.$ and $\left.\mathrm{NaCl}\right)$ are known to exhibit concentration-dependent bubble coalescence effects (Craig et al., 1993a, b; Henry et al., 2007). Typically, increasing the solution salt concentration up to $0.01 \mathrm{M}$ leads to minimal decreases in bubble coalescence relative to pure water (Henry et al., 2007). As a result, total bubble number concentrations increased only gradually for $\mathrm{NaCl}$ when solution concentrations in the LSA generator increased from 0.05 to $1 \mathrm{~g} \mathrm{~kg}^{-1} \mathrm{NaCl}(0.00086-0.017 \mathrm{M})$. However, when the solutions entered the $0.01-0.2 \mathrm{M}$ solution concentration range $\left(1-35 \mathrm{~g} \mathrm{~kg}^{-1} \mathrm{NaCl}\right)$, where bubble coalescence is known to decrease significantly (Sovechles and Waters, 2015), a greater rate of increase in total bubble number concentration with increased solution concentration was observed (Fig. 7c). These results indicate that the different ionic concentrations affected bubble coalescence and bubble concentrations in this study, which in turn influenced aerosol concentrations produced by bubble bursting.

\subsubsection{Aerosol generation from standard salts}

The aerosol size distributions for the two standard salt solutions representative of seawater $(\mathrm{NaCl})$ and freshwater $\left(\mathrm{CaCO}_{3}\right)$ were measured as a function of solution concentration (Fig. 8a, b) to examine the effect of the dominant ion present, and ionic concentration, in solution on aerosol production. At concentrations representative of the Great Lakes, 0.05 and $0.15 \mathrm{~g} \mathrm{~kg}^{-1}$, aerosol size distributions generated from solutions of $\mathrm{NaCl}$ and $\mathrm{CaCO}_{3}$ exhibited two lognormal diameter modes (Fig. 8a, b). The primary aerosol modes produced from the $0.05-0.15 \mathrm{~g} \mathrm{~kg}^{-1} \mathrm{NaCl}$ and $\mathrm{CaCO}_{3}$ solutions were larger in diameter than the secondary aerosol modes (Fig. 8a, b). This is consistent with the bimodal aerosol size
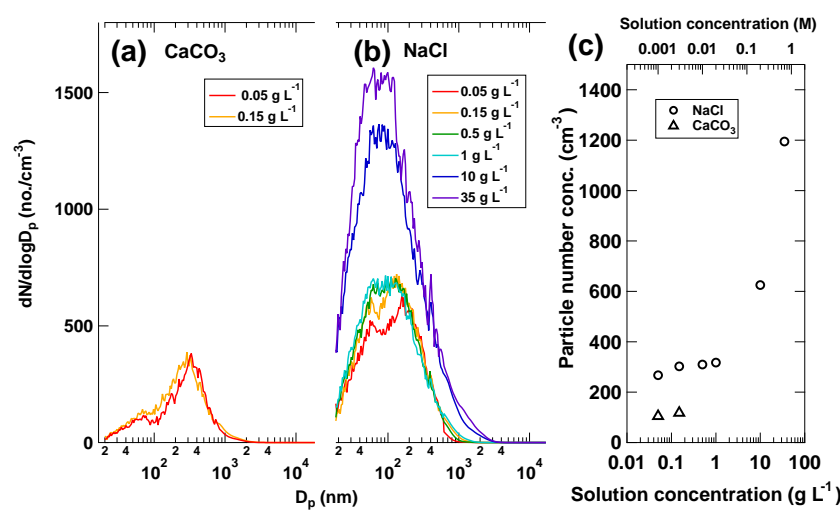

Figure 8. Average aerosol number concentration generated by the LSA generator as a function of solution concentration for (a) $\mathrm{CaCO}_{3}$ and (b) $\mathrm{NaCl}$, as well as (c) total aerosol number concentration as a function of ion composition for $\mathrm{CaCO}_{3}$ and $\mathrm{NaCl}$.

distributions generated from the synthetic freshwater (total inorganic ion content $=0.12 \mathrm{~g} \mathrm{~kg}^{-1}$ ) and Lake Michigan freshwater (total inorganic ion content $=0.14 \mathrm{~g} \mathrm{~kg}^{-1}$ ), which also exhibited primary aerosol modes higher in diameter than the secondary aerosol modes (Sect. 3.2.2). At higher concentrations $\left(0.5-35 \mathrm{~g} \mathrm{~kg}^{-1}\right)$ more representative of seawater total inorganic ion content $\left(35 \mathrm{~g} \mathrm{~kg}^{-1}\right)$, the $\mathrm{NaCl}$ solutions produced unimodal size distributions (Fig. 8b), consistent with the unimodal number size distribution produced from synthetic seawater (Fig. 4a). The bimodal aerosol number size distribution that was observed for all freshwater concentration (0.05-0.15 $\left.\mathrm{g} \mathrm{kg}^{-1}\right)$ standard salt solutions (Fig. 8a, b) and the freshwater solutions (Fig. 4a) indicates that solution concentration is important in determining aerosol size distribution.

Solution composition, as well as concentration, was observed to affect the aerosol size distribution (Fig. 8). The two lognormal modes of the aerosol size distribution produced from the $0.05 \mathrm{~g} \mathrm{~kg}^{-1}$ concentration solutions were located at a higher diameters for $\mathrm{CaCO}_{3}(83 \pm 8 ; 340 \pm 20 \mathrm{~nm})$ compared to $\mathrm{NaCl}(55 \pm 9 ; 210 \pm 20 \mathrm{~nm})$. When $\mathrm{CaCO}_{3}$ and $\mathrm{NaCl}$ solution concentrations increased from 0.05 to $0.15 \mathrm{~g} \mathrm{~kg}^{-1}$, the $\mathrm{CaCO}_{3}$ modes $(60 \pm 10 ; 290 \pm 10 \mathrm{~nm})$ remained at higher diameters than the $\mathrm{NaCl}$ modes $(40 \pm 6$; $140 \pm 10 \mathrm{~nm}$ ), but all modes shifted to smaller diameters (Fig. 9b). The mode diameter of the $35 \mathrm{~g} \mathrm{~kg}^{-1} \mathrm{NaCl}$ solution $(81 \pm 3 \mathrm{~nm})$ was smaller than the mode of the $\mathrm{NaCl}$ dominant synthetic seawater solution $(110 \pm 4 \mathrm{~nm})$, suggesting that mixtures of ions affect aerosol size distributions. In addition, the lognormal modal diameters produced from the $0.15 \mathrm{~g} \mathrm{~kg}^{-1} \mathrm{CaCO}_{3}$ solution $(60 \pm 10 ; 290 \pm 10 \mathrm{~nm})$ were slightly smaller in comparison to the synthetic freshwater aerosol size distribution modes $(80 \pm 10 ; 300 \pm 40 \mathrm{~nm})$, again indicating that mixtures of ions affect aerosol size distributions. As the Great Lakes have a wide and evolving range of inorganic ion compositions and concentration 
(Fig. 1) (Chapra et al., 2012), the dependence of aerosol size distributions on solution composition and concentration observed in this study could significantly impact the range of LSA size distributions in the atmosphere.

The total aerosol concentrations generated from $\mathrm{CaCO}_{3}$ and $\mathrm{NaCl}$ solutions increased with solution concentration (Fig. 8) in a similar manner to the increase in total bubble concentrations generated with increased solution concentration (Fig. 7). The total aerosol concentration increased slowly between solution concentrations of 0.05 and $1.0 \mathrm{~g} \mathrm{~kg}^{-1}$, reflecting the slow increase in bubble concentrations over this concentration range (Fig. 7). At solution concentrations greater than $1.0 \mathrm{~g} \mathrm{~kg}^{-1}$, a shift to a larger increase in total aerosol concentration with increased solution concentration occurred. The change in relationship between solution and aerosol concentration at solution concentrations above $1.0 \mathrm{~g} \mathrm{~kg}^{-1}(\mathrm{NaCl}=0.017 \mathrm{M})$ reflects the change in bubble concentration above $1.0 \mathrm{~g} \mathrm{~kg}^{-1}(\mathrm{NaCl}=0.017 \mathrm{M})$ observed in this study (Fig. 8c) and the known transition in bubble coalescence behavior that occurs above ionic concentrations of $0.01 \mathrm{M}$ (Sovechles and Waters, 2015). Further, the direct relationship between bubble and aerosol concentrations for the increasing standard salt solution concentrations aligns well with the direct relationship in bubble and aerosol concentrations for freshwater and seawater solutions (Fig. 5). These results confirm that there is a direct relationship between solution concentration, bubble concentration, and aerosol concentration that will result in the production of a lower number of particles from wave breaking in low-salt freshwater compared to wave breaking in high-salt seawater.

\section{Conclusions}

We have constructed and demonstrated the capabilities of a newly developed LSA generator to reproduce SSA using marine salinities and to probe LSA generation under freshwaterrelevant low-salt concentrations. The LSA generator utilizes plunging jets to entrain air and generate bubbles, similar to other SSA generation techniques, but with modifications, such as the addition of mesh caps on the plunging jet outlets to obtain more accurate air entrainment by increasing surface roughness of the plunging jet (Stokes et al., 2013; Zhu et al., 2000). The LSA generator requires lower sample volume to generate aerosols compared to other plunging jet SSA generators (Salter et al., 2014). The lower solution volume requirement $(4 \mathrm{~L})$ allowed for generation of LSA from a variety of samples, including a freshwater sample collected from Lake Michigan. This increases the ease of analyzing a large number of freshwater samples, which will be necessary to probe how the differences in composition between freshwater locations (Chapra et al., 2012; Shuchman et al., 2013) affect aerosol generation. Recent combined field and lake spray aerosol generator results show the composition of LSA particles at a site without a harmful algal bloom to be predominantly calcium carbonate with organic and biological components (Axson et al., 2016a).

This LSA-generator-enabled laboratory study of LSA production allowed a direct investigation into the influence of salt concentration and composition on aerosol production from bubble bursting in freshwater and simplified model systems. The results show that freshwater bubble bursting, expected during periods of high winds and high waves over freshwater environments such as the Laurentian Great Lakes, will produce LSA. Distinct differences in the production and properties of LSA compared to SSA from marine environments are observed. For example, the lower concentration of salts in freshwater compared to seawater leads to lower number concentrations of bubbles in freshwater compared to seawater, such that a lower number concentration of LSA is produced compared to SSA. In addition, the differences in salt concentration between seawater and freshwater lead to a size distribution of LSA that is bimodal compared to the unimodal SSA. The primary and secondary lognormal modes of the aerosol size distribution generated from the Lake Michigan freshwater sample were centered at larger diameters $(180 \pm 20,46 \pm 6 \mathrm{~nm})$ than the aircraft-measured mode (15-40 nm) over Lake Michigan by Slade et al. (2010). Lower RH aloft and the presence of other aerosol present near the modes of the LSA size distribution in the ambient atmosphere sampled by Slade et al. (2010) could explain the lack of agreement with this laboratory study and reported LSA diameter modes. The larger LSA observed in this study could better activate as CCN (Lewis and Schwartz, 2004) than the smaller LSA observed by Slade et al. (2010) and the smaller SSA observed in this study and others; however, further studies are needed.

While this laboratory study represents a fundamental exploration of the role of inorganic salts in LSA production, the role of organic and biological material present in lake water in determining LSA production and properties is currently poorly understood. Organic, heavy metal, and biological content of seawater is known to affect SSA production and properties (Ault et al., 2013b; Burrows et al., 2014; Facchini et al., 2008; Guasco et al., 2013; Lee et al., 2015; O’Dowd et al., 2008; Prather et al., 2013; Quinn et al., 2014), and thus organic and biological components of lake water are likely to affect LSA production, properties, and heterogeneous chemistry (Ault et al., 2013a, 2014; Ryder et al., 2014). This study observed the effect of organic and biological materials in lake water on LSA through the differences in the aerosol size distributions and aerosol circularity generated from the organicand biological-rich Lake Michigan freshwater sample, and the organic- and biological-free synthetic freshwater. Lake water has a higher ratio of organic to inorganic content than seawater (Chapra et al., 2012; Pilson, 2013), so the organic content in lake water likely plays a larger role in LSA than the organic content in SSA. In addition, recent increases in toxic cyanobacteria blooms in the Great Lakes (Michalak et al., 2013) may impact air quality if toxic components are 
aerosolized with LSA, as has been observed for marine algal blooms (i.e., red tides) (Cheng et al., 2010; Woodcock, 1948). Therefore, future studies are needed to determine the effect of the organic and biological content in freshwater on aerosol production and resulting properties.

The impact of LSA on radiative forcing and precipitation in the Great Lakes region is currently uncertain (Chung et al., 2011) and more detailed modeling based on particle mixing state is needed (Bauer et al., 2013). For example, SSA impacts radiative forcing directly through scattering and indirectly by acting as CCN (Collins et al., 2013), which influences cloud properties and precipitation patterns (Wise et al., 2009), and LSA could have a similar effect. The Great Lakes' impact on downwind cloud cover and precipitation, known as the lake effect, is well known, and LSA could play a role in this process (Scott and Huff, 1996). The contribution of LSA to regional aerosol concentrations may have seasonality, with the highest production likely occurring in the fall and late spring when wind speeds are highest and the lakes are not covered in ice. With global climate change predicted to decrease ice extent during winter (Wang et al., 2012) and observed increases in wind speed, linked to warming temperatures (Desai et al., 2009), the impact of LSA is expected to increase in the future.

\section{Data availability}

All data sets presented in this work can be accessed through contact with the corresponding authors.

\section{The Supplement related to this article is available online at doi:10.5194/amt-9-4311-2016-supplement.}

Acknowledgements. The University of Michigan Water Center and Dow Sustainability Fellows Program at the University of Michigan provided funding for this work. The authors would like to thank the University of Michigan College of Literature, Science, and the Arts Instrument Shop for helping with construction of the LSA generator, and the Michigan Center for Materials Characterization, $(\mathrm{MC})^{2}$, at the University of Michigan is acknowledged for assistance with electron microscopy. Grant Deane of Scripps Institute of Oceanography at the University of California-San Diego is thanked for discussions regarding bubble plume analysis.

Edited by: F. Pope

Reviewed by: two anonymous referees

\section{References}

Andreae, M. O. and Rosenfeld, D.: Aerosol-cloud-precipitation interactions. Part 1. The nature and sources of cloud-active aerosols, Earth-Sci. Rev., 89, 13-41, 2008.
Atkinson, M. J. and Bingman, C.: Elemental composition of commercial seasalts, J. Aquaric. Aquat. Sci., 8, 39-43, 1997.

Ault, A. P., Moore, M. J., Furutani, H., and Prather, K. A.: Impact of emissions from the Los Angeles port region on San Diego air quality, Environ. Sci. Technol., 43, 3500-3506, 2009.

Ault, A. P., Williams, C. R., White, A. B., Neiman, P. J., Creamean, J. M., Gaston, C. J., Ralph, F. M., and Prather, K. A.: Detection of Asian dust in California orographic precipitation, J. Geophys. Res., 116, D16205, doi:10.1029/2010JD015351, 2011.

Ault, A. P., Peters, T. M., Sawvel, E. J., Casuccio, G. S., Willis, R. D., Norris, G. A., and Grassian, V. H.: Single-particle SEM-EDX analysis of iron-containing coarse particulate aatter in an urban environment: sources and distribution of iron within Cleveland, Ohio, Environ. Sci. Technol., 46, 4331-4339, 2012.

Ault, A. P., Guasco, T. L., Ryder, O. S., Baltrusaitis, J., CuadraRodriguez, L. A., Collins, D. B., Ruppel, M. J., Bertram, T. H., Prather, K. A., and Grassian, V. H.: Inside versus outside: ion redistribution in nitric acid reacted sea spray aerosol particles as determined by single particle analysis, J. Am. Chem. Soc., 135, 14528-14531, 2013a.

Ault, A. P., Moffet, R. C., Baltrusaitis, J., Collins, D. B., Ruppel, M. J., Cuadra-Rodriguez, L. A., Zhao, D., Guasco, T. L., Ebben, C. J., Geiger, F. M., Bertram, T. H., Prather, K. A., and Grassian, V. H.: Size-dependent changes in sea spray serosol composition and properties with different seawater conditions, Environ. Sci. Technol., 47, 5603-5612, 2013b.

Ault, A. P., Guasco, T. L., Baltrusaitis, J., Ryder, O. S., Trueblood, J. V., Collins, D. B., Ruppel, M. J., Cuadra-Rodriguez, L. A., Prather, K. A., and Grassian, V. H.: Heterogeneous reactivity of nitric acid with nascent sea spray aerosol: large differences observed between and within individual particles, J. Phys. Chem. Lett., 5, 2493-2500, doi:10.1021/jz5008802, 2014.

Axson, J. L., Creamean, J. M., Bondy, A. L., Capracotta, S. S., Warner, K. Y., and Ault, A. P.: An in situ method for sizing insoluble residues in precipitation and other aqueous samples, Aerosol Sci. Technol., 49, 24-34, 2014.

Axson, J. L., May, N. W., Colón-Bernal, I. D., Pratt, K. A., and Ault, A. P.: Lake Spray Aerosol: A Chemical Signature from Individual Ambient Particles, Environ. Sci. Technol., doi:10.1021/acs.est.6b01661, in press, 2016a.

Axson, J. L., Shen, H., Bondy, A. L., Landry, C. C., Welz, J., Creamean, J. M., and Ault, A. P.: Transported Mineral Dust Deposition Case Study at a Hydrologically Sensitive Mountain Site: Size and Composition Shifts in Ambient Aerosol and Snowpack, Aerosol and Air Quality Resarch, 16, 555-567, 2016 b.

Bauer, S. E., Ault, A., and Prather, K. A.: Evaluation of aerosol mixing state classes in the GISS modelE-MATRIX climate model using single-particle mass spectrometry measurements, J. Geophys. Res.-Atmos., 118, 9834-9844, 2013.

Biddanda, B. A. and Cotner, J. B.: Love Handles in Aquatic Ecosystems: The Role of Dissolved Organic Carbon Drawdown, Resuspended Sediments, and Terrigenous Inputs in the Carbon Balance of Lake Michigan, Ecosystems, 5, 431-445, 2002.

Blanchard, D. C.: The electrification of the atmosphere by particles from bubbles in the sea, Prog. Oceanogr., 1, 73-202, 1963.

Blanchard, D. C. and Syzdek, L. D.: Electrostatic collection of jet and film drops, Limnol. Oceanogr., 20, 762-774, 1975. 
Blanchard, D. C. and Woodcock, A. H.: Bubble Formation and Modification in the Sea and its Meteorological Significance, Tellus, 9, 145-158, 1957.

Blenkinsopp, C. E. and Chaplin, J. R.: Void fraction measurements and scale effects in breaking waves in freshwater and seawater, Coast. Eng., 58, 417-428, 2011.

Bowyer, P. A.: Video measurements of near-surface bubble spectra, J. Geophys. Res.-Oceans, 106, 14179-14190, 2001.

Burrows, S. M., Ogunro, O., Frossard, A. A., Russell, L. M., Rasch, P. J., and Elliott, S. M.: A physically based framework for modeling the organic fractionation of sea spray aerosol from bubble film Langmuir equilibria, Atmos. Chem. Phys., 14, 1360113629, doi:10.5194/acp-14-13601-2014, 2014.

Carey, W. M., Fitzgerald, J. W., Monahan, E. C., and Wang, Q.: Measurement of the sound produced by a tipping trough with fresh and salt water, J. Acoust. Soc. Am., 93, 3178, doi:10.1121/1.405702, 1993.

Chapra, S. C., Dove, A., and Warren, G. J.: Long-term trends of Great Lakes major ion chemistry, J. Gt. Lakes Res., 38, 550-560, 2012.

Cheng, Y. S., Zhou, Y., Pierce, R. H., Henry, M., and Baden, D. G.: Characterization of Florida red tide aerosol and the temporal profile of aerosol concentration, Toxicon, 55, 922-929, 2010.

Chung, S. H., Basarab, B. M., and VanReken, T. M.: Regional impacts of ultrafine particle emissions from the surface of the Great Lakes, Atmos. Chem. Phys., 11, 12601-12615, doi:10.5194/acp11-12601-2011, 2011.

Collins, D. B., Ault, A. P., Moffet, R. C., Ruppel, M. J., CuadraRodriguez, L. A., Guasco, T. L., Corrigan, C. E., Pedler, B. E., Azam, F., Aluwihare, L. I., Bertram, T. H., Roberts, G. C., Grassian, V. H., and Prather, K. A.: Impact of marine biogeochemistry on the chemical mixing state and cloud forming ability of nascent sea spray aerosol, J. Geophys. Res.-Atmos., 118, 85538565, 2013.

Collins, D. B., Zhao, D. F., Ruppel, M. J., Laskina, O., Grandquist, J. R., Modini, R. L., Stokes, M. D., Russell, L. M., Bertram, T. H., Grassian, V. H., Deane, G. B., and Prather, K. A.: Direct aerosol chemical composition measurements to evaluate the physicochemical differences between controlled sea spray aerosol generation schemes, Atmos. Meas. Tech., 7, 3667-3683, doi:10.5194/amt-7-3667-2014, 2014.

Craig, V. S. J., Ninham, B. W., and Pashley, R. M.: Effect of electrolytes on bubble coalescence, Nature, 364, 317-319, 1993a.

Craig, V. S. J., Ninham, B. W., and Pashley, R. M.: The effect of electrolytes on bubble coalescence in water, J. Phys. Chem., 97, 10192-10197, 1993b.

Creamean, J. M., Suski, K. J., Rosenfeld, D., Cazorla, A., DeMott, P. J., Sullivan, R. C., White, A. B., Ralph, F. M., Minnis, P., Comstock, J. M., Tomlinson, J. M., and Prather, K. A.: Dust and biological aerosols from the Sahara and Asia influence precipitation in the western US, Science, 339, 1572-1578, 2013.

Creamean, J. M., Ault, A. P., White, A. B., Neiman, P. J., Ralph, F. M., Minnis, P., and Prather, K. A.: Impact of interannual variations in sources of insoluble aerosol species on orographic precipitation over California's central Sierra Nevada, Atmos. Chem. Phys., 15, 6535-6548, doi:10.5194/acp-15-6535-2015, 2015.

Creamean, J. M., Axson, J. L., Bondy, A. L., Craig, R. L., May, N. W., Shen, H., Weber, M. H., Pratt, K. A., and Ault, A. P.: Changes in precipitating snow chemistry with location and ele- vation in the California Sierra Nevada, J. Geophys. Res.-Atmos., 121, doi:10.1002/2015JD024700, 2016.

Deane, G. B.: Sound generation and air entrainment by breaking waves in the surf zone, J. Acoust. Soc. Am., 102, 2671, doi:10.1121/1.420321, 1997.

Deane, G. B. and Stokes, M. D.: Air Entrainment Processes and Bubble Size Distributions in the Surf Zone, J. Phys. Oceanogr., 29, 1393-1403, 1999.

Deane, G. B. and Stokes, M. D.: Scale dependence of bubble creation mechanisms in breaking waves, Nature, 418, 839-844, 2002.

DeMott, P. J., Prenni, A. J., Liu, X., Kreidenweis, S. M., Petters, M. D., Twohy, C. H., Richardson, M. S., Eidhammer, T., and Rogers, D. C.: Predicting global atmospheric ice nuclei distributions and their impacts on climate, P. Natl. Acad. Sci. USA, 107, 1121711222, 2010.

DeMott, P. J., Hill, T. C. J., McCluskey, C. S., Prather, K. A., Collins, D. B., Sullivan, R. C., Ruppel, M. J., Mason, R. H., Irish, V. E., Lee, T., Hwang, C. Y., Rhee, T. S., Snider, J. R., McMeeking, G. R., Dhaniyala, S., Lewis, E. R., Wentzell, J. J. B., Abbatt, J., Lee, C., Sultana, C. M., Ault, A. P., Axson, J. L., Diaz Martinez, M., Venero, I., Santos-Figueroa, G., Stokes, M. D., Deane, G. B., Mayol-Bracero, O. L., Grassian, V. H., Bertram, T. H., Bertram, A. K., Moffett, B. F., and Franc, G. D.: Sea spray aerosol as a unique source of ice nucleating particles, P. Natl. Acad. Sci. USA, 113, 5797-5803, 2016.

Desai, A. R., Austin, J. A., Bennington, V., and McKinley, G. A.: Stronger winds over a large lake in response to weakening air-tolake temperature gradient, Nat. Geosci., 2, 855-858, 2009.

Doubrawa, P., Barthelmie, R. J., Pryor, S. C., Hasager, C. B., Badger, M., and Karagali, I.: Satellite winds as a tool for offshore wind resource assessment: The Great Lakes Wind Atlas, Remote Sens. Environ., 168, 349-359, 2015.

Facchini, M. C., Rinaldi, M., Decesari, S., Carbone, C., Finessi, E., Mircea, M., Fuzzi, S., Ceburnis, D., Flanagan, R., Nilsson, E. D., de Leeuw, G., Martino, M., Woeltjen, J., and O’Dowd, C. D.: Primary submicron marine aerosol dominated by insoluble organic colloids and aggregates, Geophys. Res. Lett., 35, doi:10.1029/2008GL034210, 2008.

Fuentes, E., Coe, H., Green, D., de Leeuw, G., and McFiggans, G.: Laboratory-generated primary marine aerosol via bubblebursting and atomization, Atmos. Meas. Tech., 3, 141-162, doi:10.5194/amt-3-141-2010, 2010.

Guasco, T. L., Cuadra-Rodriguez, L. A., Pedler, B. E., Ault, A. P., Collins, D. B., Zhao, D., Kim, M. J., Ruppel, M. J., Wilson, S. C., Pomeroy, R. S., Grassian, V. H., Azam, F., Bertram, T. H., and Prather, K. A.: Transition Metal Associations with Primary Biological Particles in Sea Spray Aerosol Generated in a Wave Channel, Environ. Sci. Technol., 48, 1324-1333, 2013.

Henry, C. L., Dalton, C. N., Scruton, L., and Craig, V. S. J.: IonSpecific Coalescence of Bubbles in Mixed Electrolyte Solutions, J. Phys. Chem. C, 111, 1015-1023, 2007.

Hultin, K. A. H., Nilsson, E. D., Krejci, R., Mårtensson, E. M., Ehn, M., Hagström, Å., and de Leeuw, G.: In situ laboratory sea spray production during the Marine Aerosol Production 2006 cruise on the northeastern Atlantic Ocean, J. Geophys. Res., 115, doi:10.1029/2009JD012522, 2010.

Khlystov, A., Stanier, C., and Pandis, S. N.: An algorithm for combining electrical mobility and aerodynamic size distributions data 
when measuring ambient aerosol, Aerosol Sci. Technol., 38, 229-238, 2004.

King, S. M., Butcher, A. C., Rosenoern, T., Coz, E., Lieke, K. I., de Leeuw, G., Nilsson, E. D., and Bilde, M.: Investigating primary marine aerosol properties: $\mathrm{CCN}$ activity of sea salt and mixed inorganic-organic particles, Environ. Sci. Technol., 46, 1040510412, 2012.

Lee, C., Sultana, C. M., Collins, D. B., Santander, M. V., Axson, J. L., Malfatti, F., Cornwell, G. C., Grandquist, J. R., Deane, G. B., Stokes, M. D., Azam, F., Grassian, V. H., and Prather, K. A.: Advancing Model Systems for Fundamental Laboratory Studies of Sea Spray Aerosol Using the Microbial Loop, J. Phys. Chem. A, 119, 8860-8870, 2015.

Lessard, R. R. and Zieminski, S. A.: Bubble Coalescence and Gas Transfer in Aqueous Electrolytic Solutions, Ind. Eng. Chem. Fund., 10, 260-269, 1971.

Lewis, E. R. and Schwartz, S. E.: Sea Salt Aerosol Production: Mechanisms, Methods, Measurements, and Models - A Critical Review, American Geophysical Union, Washington DC, USA, ISBN: 087590-417-3, 2004.

Lohmann, U. and Feichter, J.: Global indirect aerosol effects: a review, Atmos. Chem. Phys., 5, 715-737, doi:10.5194/acp-5-7152005, 2005.

Michalak, A. M., Anderson, E. J., Beletsky, D., Boland, S., Bosch, N. S., Bridgeman, T. B., Chaffin, J. D., Cho, K., Confesor, R., Daloglu, I., Depinto, J. V., Evans, M. A., Fahnenstiel, G. L., He, L., Ho, J. C., Jenkins, L., Johengen, T. H., Kuo, K. C., Laporte, E., Liu, X., McWilliams, M. R., Moore, M. R., Posselt, D. J., Richards, R. P., Scavia, D., Steiner, A. L., Verhamme, E., Wright, D. M., and Zagorski, M. A.: Record-setting algal bloom in Lake Erie caused by agricultural and meteorological trends consistent with expected future conditions, P. Natl. Acad. Sci. USA, 110, 6448-6452, 2013.

Moffett, B. F.: Fresh water ice nuclei, Fund. Appl. Limnol., 188, 19-23, 2016.

Monahan, E. C.: Fresh water whitecaps, J. Atmos. Sci., 26, 10261029, 1969.

Monahan, E. C. and Zietlow, C. R.: Laboratory comparisons of fresh-water and salt-water whitecaps, J. Geophys. Res., 74, 6961-6966, 1969.

Murphy, D. M., Anderson, J. R., Quinn, P. K., McInnes, L. M., Brechtel, F. J., Kreidenweis, S. M., Middlebrook, A. M., Pósfai, M., Thomson, D. S., and Buseck, P. R.: Influence of sea-salt on aerosol radiative properties in the SouthernOcean marine boundary layer, Nature, 392, 62-65, 1998.

O'Dowd, C. D., Langmann, B., Varghese, S., Scannell, C., Ceburnis, D., and Facchini, M. C.: A combined organicinorganic sea-spray source function, Geophys. Res. Lett., 35, doi:10.1029/2007GL030331, 2008.

Pilson, M. E. Q.: An Introduction to the Chemistry of the Sea, Cambridge University Press, New York, USA, 66-69, 2013.

Prather, K. A., Bertram, T. H., Grassian, V. H., Deane, G. B., Stokes, M. D., DeMott, P. J., Aluwihare, L. I., Palenik, B. P., Azam, F., Seinfeld, J. H., Moffet, R. C., Molina, M. J., Cappa, C. D., Geiger, F. M., Roberts, G. C., Russell, L. M., Ault, A. P., Baltrusaitis, J., Collins, D. B., Corrigan, C. E., Cuadra-Rodriguez, L. A., Ebben, C. J., Forestieri, S. D., Guasco, T. L., Hersey, S. P., Kim, M. J., Lambert, W. F., Modini, R. L., Mui, W., Pedler, B. E., Ruppel, M. J., Ryder, O. S., Schoepp, N. G., Sullivan, R.
C., and Zhao, D.: Bringing the ocean into the laboratory to probe the chemical complexity of sea spray aerosol, P. Natl. Acad. Sci. USA, 110, 7550-7555, 2013.

Qin, X. Y., Bhave, P. V., and Prather, K. A.: Comparison of two methods for obtaining quantitative mass concentrations from aerosol time-of-flight mass spectrometry measurements, Anal. Chem., 78, 6169-6178, 2006.

Quinn, P. K., Bates, T. S., Schulz, K. S., Coffman, D. J., Frossard, A. A., Russell, L. M., Keene, W. C., and Kieber, D. J.: Contribution of sea surface carbon pool to organic matter enrichment in sea spray aerosol, Nat. Geosci., 7, 228-232, 2014.

Repeta, D. J., Quan, T. M., Aluwihare, L. I., and Accardi, A.: Chemical characterization of high molecular weight dissolved organic matter in fresh and marine waters, Geochim. Cosmochim. Acta, 66, 955-962, 2002.

Resch, F.: Oceanic Air Bubbles as Generators of Marine Aerosols, in: Oceanic Whitecaps, edited by: Monahan, E. and Niocaill, G., Oceanographic Sciences Library, Springer Netherlands, 101$112,1986$.

Ryder, O. S., Ault, A. P., Cahill, J. F., Guasco, T. L., Riedel, T. P., Cuadra-Rodriguez, L. A., Gaston, C. J., Fitzgerald, E., Lee, C., Prather, K. A., and Bertram, T. H.: On the Role of Particle Inorganic Mixing State in the Reactive Uptake of N2O5 to Ambient Aerosol Particles, Environ. Sci. Technol., 48, 1618-1627, 2014.

Salter, M. E., Nilsson, E. D., Butcher, A., and Bilde, M.: On the seawater temperature dependence of the sea spray aerosol generated by a continuous plunging jet, J. Geophys. Res.-Atmos., 119, 9052-9072, 2014.

Schneider, C. A., Rasband, W. S., and Eliceiri, K. W.: NIH Image to ImageJ: 25 years of image analysis, Nat. Methods, 9, 671-675, 2012.

Scott, R. W. and Huff, F. A.: Impacts of the Great Lakes on Regional Climate Conditions, J. Great Lakes Res., 22, 845-863, 1996.

Sellegri, K., O’Dowd, C. D., Yoon, Y. J., Jennings, S. G., and de Leeuw, G.: Surfactants and submicron sea spray generation, J. Geophys. Res.-Atmos., 111, D22215, doi:10.1029/2005JD006658, 2006.

Shuchman, R. A., Leshkevich, G., Sayers, M. J., Johengen, T. H., Brooks, C. N., and Pozdnyakov, D.: An algorithm to retrieve chlorophyll, dissolved organic carbon, and suspended minerals from Great Lakes satellite data, J. Gt. Lakes Res., 39, 14-33, 2013.

Slade, J. H., VanReken, T. M., Mwaniki, G. R., Bertman, S., Stirm, B., and Shepson, P. B.: Aerosol production from the surface of the Great Lakes, Geophys. Res. Lett., 37, L18807, doi:10.1029/2010GL043852, 2010.

Slauenwhite, D. E. and Johnson, B. D.: Bubble shattering: Differences in bubble formation in fresh water and seawater, J. Geophys. Res., 104, 3265, doi:10.1029/1998JC900064, 1999.

Sovechles, J. M. and Waters, K. E.: Effect of ionic strength on bubble coalescence in inorganic salt and seawater solutions, AIChE J., 61, 2489-2496, 2015.

Spiel, D. E.: The number and size of jet drops produced by air bubbles bursting on a fresh water surface, J. Geophys. Res., 99, 325338, 1994a.

Spiel, D. E.: The sizes of the jet drops produced by air bubbles bursting on sea- and fresh-water surfaces, Tellus B, 46, 325-338, 1994b. 
Stokes, M. D., Deane, G. B., Prather, K., Bertram, T. H., Ruppel, M. J., Ryder, O. S., Brady, J. M., and Zhao, D.: A Marine Aerosol Reference Tank system as a breaking wave analogue for the production of foam and sea-spray aerosols, Atmos. Meas. Tech., 6, 1085-1094, doi:10.5194/amt-6-1085-2013, 2013.

Veron, F.: Ocean Spray, Annu. Rev. Fluid Mech., 47, 507-538, 2015.

Wang, J., Bai, X., Hu, H., Clites, A., Colton, M., and Lofgren, B.: Temporal and Spatial Variability of Great Lakes Ice Cover, 19732010*, J. Clim., 25, 1318-1329, 2012.

Wise, M. E., Freney, E. J., Tyree, C. A., Allen, J. O., Martin, S. T., Russell, L. M., and Buseck, P. R.: Hygroscopic behavior and liquid-layer composition of aerosol particles generated from natural and artificial seawater, J. Geophys. Res., 114, D03201, doi:10.1029/2008JD010449, 2009.
Woodcock, A. H.: Note Concerning Human Respiratory Irritation Associated with High Concentrations of Plankton and Mass Mortality of Marine Organisms, J. Mar. Res., 7, 56-62, 1948.

Zábori, J., Matisans, M., Krejci, R., Nilsson, E. D., and Ström, J.: Artificial primary marine aerosol production: a laboratory study with varying water temperature, salinity, and succinic acid concentration, Atmos. Chem. Phys., 12, 10709-10724, doi:10.5194/acp-12-10709-2012, 2012.

Zhu, Y., Oğuz, H. N., and Prosperetti, A.: On the mechanism of air entrainment by liquid jets at a free surface, J. Fluid Mech., 404, 151-177, 2000. 